\title{
Notes and Insights
}

\section{Social Support and Social Structure}

\author{
James S. House
}

University of Michigan

\begin{abstract}
The burgeoning study of social support in relation to social stress and health would benefit from increased attention to issues of social structure. Three aspects of social relationships, all often referred to as social support, must be more clearly distinguished(1) their existence or quantity (i.e., social integration), (2) their formal structure (i.e., social networks), and (3) their functional or behavioral content (i.e, the most precise meaning of "social support") - and the causal relationships between the structure of social relationships (social integration and networks) and their functional content (social support) must be more clearly understood. Research and theory are needed on the determinants of social integration, networks, and support as well as their consequences for stress and health. Among potential determinants, macrosocial structures and processes particularly merit attention.
\end{abstract}

The study of "social support," especially in relation to health, has emerged seemingly out of nowhere in the last decade. A search of the Social Science Citation Index for articles with the term "social support" in their titles revealed an almost geometric rate of growth in the late 1970s: an average of 2 such articles per year between 1972 and 1976, 7 in 1977, 10 in 1978, 21 in 1979, and 43 by 1981 (see House and Kahn, 1985; House, 1986). A more recent search revealed continuing, though more linear, growth in the early 1980s: 50 articles in 1982, 60 in 1983, 73 in 1984 , and 110 in 1985.

In many ways this is not a new area of research at all, but rather

\footnotetext{
- Preparation of this paper has been supported in part by Public Health Service grants (\#1P01AG05561) from the National Institute of Aging and (\#5T32MH16806 and 5P50MH38330) from the National Institute of Mental Health, and by a Fellowship from the John Simon Guggenheim Memorial Foundation. A previous version was presented at the Annual Meetings of the American Sociological Association, August 1985. I am indebted to Thomas Pettigrew and an anonymous referee for helpful comments.

(1) 1987 by the Eastern Sociological Society. All rights reserved.

0884-8971/87/0201-0135\$1.50
} 
represents a rediscovery and redirection of old sociological and social science concerns with interpersonal relationships and their effects on health and well-being (cf. Cobb, 1976; Hall and Wellman, 1985). Unique to the current spate of interest in social support, however, has been a focus on the potential of social relationships to promote and maintain physical and mental health, and especially to buffer or ameliorate the potential deleterious effects of psychosocial stress on health.

Evidence that social support can reduce morbidity and mortality, lessen exposure to psychosocial stress and perhaps other health hazards, and buffer the impact of stress on health is now available from diverse types of studies: laboratory experimental studies of animals as well as humans, cross-sectional and retrospective field studies of human populations, and growing numbers of longitudinal or prospective field studies as well. Although the results of individual studies are usually open to alternative interpretations, the pattern of results across the full range of studies strongly suggests that what are variously termed social relationships, social networks, and social support have important causal effects on health, exposure to stress, and the relationship between stress and health (House, 1981a). This burgeoning literature has elicited many excellent reviews and assessments of the strengths and weaknesses of this evidence, which I will not attempt to replicate or even summarize here (see Berkman, 1985; Broadhead et al., 1983; Cohen and Wills, 1985; Cohen and Syme, 1985; and Kessler and McLeod, 1985, for some of the best and most recent examples of this genre and Israel and Rounds [forthcoming] for a review of reviews).

Because of its origin in the health sciences and its concern with health as a dependent variable, the study of social support has not benefited as much as it could or should from the application of extant theoretical and conceptual perspectives of psychology and especially sociology. The study of social support is an inherently social psychological problem. Thus, the present paper attempts to utilize a distinctly sociological variant or face of social psychology (i.e., House, 1977; 1981b) the study of social structure and personality-to identify and clarify some important gaps and paradoxes in the study of social support. Central to dealing with these gaps and paradoxes is increasing attention to the unique disciplinary concern of sociology - that is, social structure.

The present focus on social structure in no way negates the need for more attention to the psychology of social support as well (cf. House, 1981a:90-94). Personality and social psychologists have emphasized that how much support a person actually receives may be as much or more a function of how well individuals generate and utilize supportive relationships as of how much support is available or provided by the environment or social structure in which they are located (e.g., Heller, 1979). However, empirical attempts to explain social support effects in 
terms of personality have not been very successful (Wethington and Kessler, 1986). Psychologists have also been among those most attentive to the negative as well as the positive effects of social support-a point to which we return below. The present paper, however, emphasizes issues which psychologists and epidemiologists have neglectedthe role of social structure in understanding the nature, sources, and generally positive effects of social relationships and supports.

\section{STRUCTURES AND SENTIMENTS OF SOCIAL SUPPORT}

One of the first things in the social support literature that strikes one, perhaps I should say that confounds or even astounds one, is that there is no consensus on the conceptualization and measurement of social support. The term social support, and related terms such as social integration and social networks, are often used interchangeably to refer to three distinct aspects of social relationships-their existence or quantity, their formal stucture, and their functional content or the degree to which they involve flows of affect or emotional concern, instrumental or tangible aid, information, and the like (Gottlieb, 1985; House and Kahn, 1985). When used in more careful and restricted ways, the term "social support" is most commonly used to refer to the last of these aspects of relationships--their functional content. Similarly, "social network" is most often and appropriately used to refer to the structures existing among dyadic ties (e.g., reciprocity, multiplexity, frequency) or among a set of relationships (e.g., their density, homogeneity, or boundedness). Finally, terms like "social integration" or "isolation" usually refer to the mere existence or quantity of social relationships.

These conceptual distinctions seem to make a difference empirically, with measures of social integration being associated with better physical and mental health regardless of exposure to stress, while measures of social support (usually phrased as general emotional concern or perceived availability of emotional or instrumental support in the face of stress) often buffer the impact of stress, especially on mental health, and only sometimes have main or additive effects on health as well (Kessler and McLeod, 1985; Cohen and Wills, 1985). The health effects of social network characteristics are limited, but some such measures seem to have been important in certain situations (e.g., lower density may facilitate adaptation to divorce or job loss).

What is most interesting for present purposes, however, is that two of these concepts-social integration and social networks-are measures of social structures, while social support is most often measured in terms of perceived psychological sentiments. Because very few studies include measures of two, much less all, of these aspects of social relationships, we do not presently understand the relationship between 
FIGURE 1. A Model for Studying Social Relationships, Networks, and Support in Relation to Each Other and to Stress and Health.

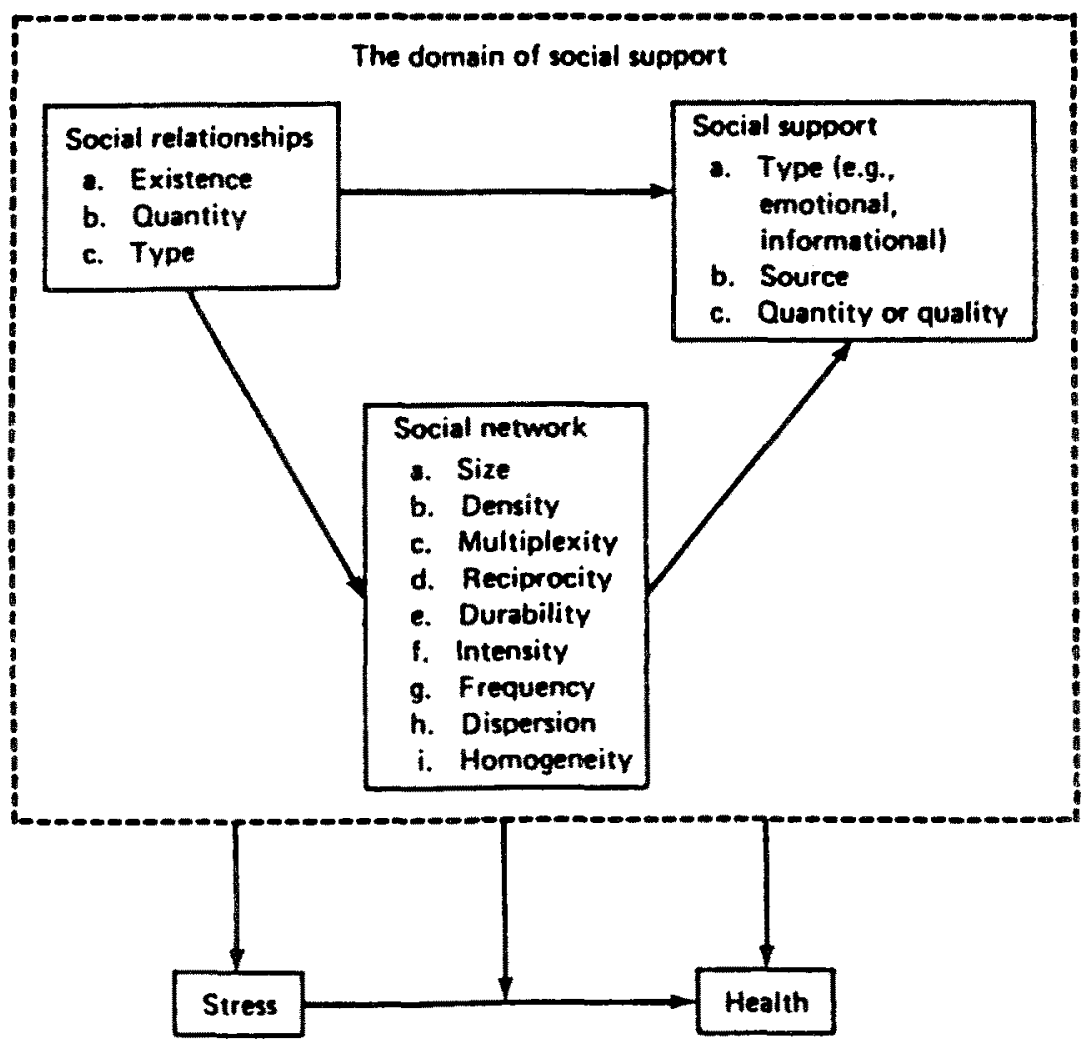

Source: House and Kahn, 1985.

these structures and sentiments regarding social relationships, nor do we understand how and why each of them may affect levels of stress, health, or the relationship between stress and health.

Figure 1 provides a simple model of the relationships among these three aspects of social relationships and of their relationships to stress and health. The figure suggests that the existence of social relationships is a necessary precondition or cause of network structure and that both of these may affect sentiments of social support. For simplicity's sake, Figure 1 uses one set of arrows to represent how each of the domains or aspects of social relationships can affect stress or health, but recognizes that each of them may reduce stress, improve health, or buffer the relationship between stress and health.

Figure 1 suggests some simple and basic, but as yet largely unanswered, questions for future research and theoretical development. 
What are the effects of social integration or isolation and of network structure on perceived sentiments of social support? To what extent are the effects of social integration on stress and health mediated through people's sentiments of being supported by others, and to what extent do they operate by other mechanisms? Conversely, are some of the observed effects of sentiments of social support merely spurious products of their association with social integration? And so on.

Limited existing evidence can only hint at the answers to these questions. As already noted, measures of social integration largely manifest direct additive relationships to health, while sentiments of support frequently show interactive or buffering effects. This suggests that social integration and social support have somewhat independent effects on health, and may have those effects through quite different social psychological processes (cf. Kessler and McLeod, 1985). Studies that have included measures of both social integration and sentiments of social support (such as a study of the psychosocial and health effects of unemployment in which we are currently engaged) find that the relationship between these two aspects of social relationships is modest at best $(\mathrm{r} \approx .1$ to .3$)$. Thus, it is unlikely that sentiments of social support can account for all effects of social integration or vice versa. In one of the few studies (and the only prospective mortality study) to measure both social integration and perceived social support, Blazer (1982) found both integration and support significantly predictive of mortality in a sample of elderly persons, but the impact on mortality of perceived support was greater, and the relationship of social integration with mortality was substantially mediated through perceived support. Further research and theory is necessary to understand these issues more clearly.

Three principles for analyzing how and why any social structure is related to individual attitudes and behavior could usefully be applied to understanding how social relationships, networks, and sentiments of support relate to each other and to stress and health: (1) the components, (2) proximity, and (3) psychological principles (House, 1981b). That is, we must attend to what components of social relationships and networks are most relevant to perceived support, how these structures become proximate stimuli for individuals, and how and why, psychologically, they should alter perceptions of support. This approach involves studying how persisting patterns of behavior by others, which after all is what we mean by social structure, affect psychological sentiments or perceptions of being supported.

Existing evidence suggests that behavior that is intended to be, or potentially could be, supportive is not always so perceived (Wortman and Lehman, 1985). Further, some data suggest that while perceptions of support are generally associated positively with health and well-being, reports of actual supportive transactions are sometimes unrelated or even 
negatively related to health and well-being. There are several potential explanations for these apparently paradoxical relationships. Perceptions of the availability of support may modify the perception of potentially stressful events or situations, so that they are experienced as less threatening, thus alleviating the need for actual supportive behavior. Levels of supportive behaviors should increase with levels of stress, and although the supportive behavior may alleviate the impact of stress, those reporting more received support may still be worse off than those reporting less or no received support. Finally, actual supportive behaviors and transactions may, in fact, be a mixed blessing, in which others are as likely to disappoint us as to sustain us. To unravel seeming paradoxes and choose among these potential explanations, we need more careful microsocial and psychological analyses, using longitudinal or experimental data, of how structures and sentiments of support operate in relation to each other and in relation to levels of stress and health.

\section{SOCIAL STRUCTURAL DETERMINANTS OF SOCIAL RELATIONSHIPS AND SOCIAL SUPPORT}

There is another way in which the study of social structure and personality can inform the study of social support. Consistent with the formulation in Figure 1, recent research and writing has viewed social integration, networks, and supports as independent, intervening, or moderating variables that may affect social stress or health or the relations between stress and health. Almost no attention has been paid, however, to social relationships, networks, and supports as dependent variables, that is, to the sources and determinants of social relationships, networks, and supports as well as their consequences for stress and health.

Though recently neglected, such issues have a long and respectable intellectual heritage dating back at least to Emile Durkheim, who was interested not only in the consequences of social integration for individuals and society, but also in the social causes or determinants of the levels of social integration experienced by individuals and society. Understanding the social structural and social psychological determinants of the levels and types of social integration, networks, and supports experienced by individuals is of great practical as well as scientific interest. If we wish to modify or enhance the levels and types of social integration, networks, and supports in any population, we must understand the forces that determine them (House, 1981a:Ch. 5; Gottlieb, 1983).

Understanding how social integration and networks relate to perceptions of support, as discussed in the preceding section of this paper, begins to address these issues. Additionally, however, we must consider how more macrosocial variables and phenomena may affect the level 
and types of social integration, social networks, and sentiments of social support that characterize individuals, communities, and even total societies. For example, do large urban, small town, and rural areas produce characteristically different patterns of social relationships and organizational involvements or of supportive behavior and perceived support? How do social relationships, organizational involvements, supportive behaviors, and perceptions of support vary over the life course and across historical periods? Or what are the impacts of housing patterns, job conditions, organizational structures, or geographic and ecological factors on social integration, networks, and support? Finally, how do social integration, networks, and supports vary across individuals with varying social statuses or roles (such as gender, race, ethnicity, and socioeconomic position) or as a function of the gender, racial, ethnic or socioeconomic composition of groups, organizations, communities, or even societies?

Laymen and social scientists have numerous hypotheses and speculations on these questions, but we have only scattered empirical evidence. We have failed to think theoretically about the larger social structural determinants of social integration, networks, and support. Further, most research on support has been based on samples that are often small and usually limited to a particular organization, community, or population of persons experiencing a particular stress or health problem. Thus, those studies that have more extensive measures of social integration, networks, or supports generally have little or no variation on potential social structural determinants of these variables, while studies on more socially heterogeneous community or national samples generally contain very limited measures of social integration, networks, and supports. Hence, existing data provide only suggestive evidence on the macrosocial determinants of either microsocial structures or psychological sentiments of social support.

Surveys of national and regional populations by Veroff, Douvan, and Kulka, (1981:Ch. 9) and Fischer (1982:Ch. 19) find that respondents with higher levels of education and income generally have larger networks, more organizational involvements, and more frequent contact with network members. These studies are consistent with others that find a higher rate of divorce and lower levels of organizational involvement and church attendance among individuals of lower socioeconomic status (Dohrenwend and Dohrenwend, 1970; Moody and Gray, 1972). Limited data suggest that these individuals may also experience a lower quality of social relationships and find these relationships less useful in coping with stress (Belle, 1982; Dohrenwend and Dohrenwend, 1970). Initial results of our current study show that unemployment consistently has adverse, if modest, effects on the quantity and quality of social integration and support, and that blacks are disadvantaged relative to 


\section{Sociological Forum}

whites in levels of social integration and support. Pilisuk and Minkler (1985) document the importance of public and private supportive services in facilitating the ability of families to provide support to aging relatives. Finally, organizational research suggests that not only the absolute level of power and privilege experienced by people, but the relative distributional equality of such resources can affect the ability to develop and maintain supportive social relationships (House, 1981a). That is, inequality as well as deprivation, can be deleterious to the formation and maintenance of supportive social relationships. In sum, the absolute and relative socioeconomic status and power of individuals appear to be important, but as yet little studied, determinants of microsocial structures and sentiments of social support.

Intermediate level social structures such as groups, families, and communities also have important consequences for social integration, networks and supports. Isolation from family relationships-as through widowhood, separation, divorce, or simple aging-seems to decrease access not only to immediate marital and family relationships and supports but also to a broader array of organizational and interpersonal ties (again see Veroff, Douvan, and Kulka, 1981; Fischer, 1982; and our own data). Organizational practices can affect the ability to develop and maintain supportive relationships at work and outside of it, and the impact of work on family (as well as vice versa) becomes increasingly important as most adults, even in intact households, are employed (cf. Kanter, 1977).

The gender composition of relationships and networks appears to be an interesting determinant of the quality and consequences of social integration, networks, and support. Studies repeatedly find that men benefit more than women from being married, confirming once again the old adage-_"everyone, man or woman, needs a wife." In prospective mortality studies, being married has much more beneficial effects on longevity among men than among women. In many of these same studies, women appear to benefit more than men from contact with friends. Since friends tend to be of the same sex, the hypothesis emerges that women are better at providing social support than are men and hence that social relationships with women are more beneficial to health and well-being than relationships with men. This hypothesis has been supported in a series of studies of Rochester University students which found that for both sexes, time spent interacting with women is inversely related to felt loneliness, while amount of contact with men is unrelated to loneliness. Similarly, relationships with women are described as more intimate and self-disclosing (e.g, Wheeler, Reis, and Nezlek, 1983). Thus, women appear, on the average, to be better providers of social support than men, and we have much to learn from understanding how and why this is so. 
Women's greater capacity to form intimate relationships is not an unalloyed blessing for them, however, since they also appear to bear greater burdens than men of providing support for friends and relatives with consequent adverse effects on their mental and perhaps physical health (Kessler and McLeod, 1984). A focus on gender has also been part of discussions of the negative impact of social support on recipients. Cobb (1976) noted that excessive attention to, control of, and provision for another can be debilitating, and he thus sought to distinguish between what he termed "mothering" and "smothering." Cobb considered only "mothering" and not "smothering" to be a form of social support. The broader perspective on relationships and supports adopted here requires that we attend to positive and negative components of a wide range of social relationships. Thus, the gender composition of dyads and groups may have important implications for the quantity and quality of social integration and support received by individuals and for the consequences of that support for both the giver and receiver.

Finally, and perhaps the topic on which we have the most theory and data, the nature and size of the community in which individuals live affects the quantity and quality of individuals' social relationships. In discussing what has sometimes been termed "the community question" (Hall and Wellman, 1985), both social scientists and laymen have disputed whether urban life adversely affects the quality or quantity of social relationships. Fischer (1982) has provided the most recent and extensive data on this topic, focusing on social integration and network structure. His findings suggest that the total size of social networks does not vary greatly along the urban-rural continuum, but the composition and structure of those networks does. Rural respondents report more dense and kin-based networks, while urban respondents have more nonrelatives in their less dense networks. Religion appears to be a more important source of social integration in rural areas, while work is more important in urban areas (cf. also Cobb and Kasl, 1977).

Findings from community epidemiologic studies of social integration and mortality point to rural-urban differences in the nature of social integration and support, with implications for our methods as well as theories. Social integration, as measured by marital status, organizational involvements, and contacts with friends and relatives, has been inversely associated with mortality in several contexts-an urban area of California (Berkman and Syme, 1979), a small city in Michigan (House, Robbins, and Metzner, 1982), and a rural area of Georgia (Schoenbach et al., 1986). This relationship, however, was strongest in the urban area, weaker in the small town (at least among women), and weaker still in the rural area. One possible explanation for this trend is that the nature and bases of social integration differ between rural and urban areas, more 
for women than men. Social contacts and integration in small towns and rural areas may occur more as part of the fabric of daily life (e.g., seeing friends and relatives and even neighbors at work, while shopping, caring for children, or doing things about town) and less in the context of planned and remembered "visits" or organizational activities. Thus, the quality of social integration, networks, and supports may vary more across these areas than would appear at first from our usual measures of the sheer quantity or structure of relationships or planned activities. This issue requires further study in view of recent reports that depression may be more prevalent in urban areas, partially due to poorer quality or quantity of social relationships in those areas relative to more rural areas (Blazer et al., 1985). Attention must be paid to social integration and supports as characteristics of communities as well as of individuals' personal networks.

A concern with the social causes or determinants of socially supportive relationships seems especially appropriate at this time. Evidence from surveys of mental health in America in 1957 and 1976 (Gurin, Veroff, and Feld, 1960; Veroff, Douvan, and Kulka, 1981; Veroff, Kulka, and Douvan, 1981) indicate that the prevalence of significant informal social relationships, networks, and supports has been declining over the last quarter century while at the same time the tendency of people to call on informal sources of support in dealing with personal problems has increased. In the 1970 s compared to the 1950 s American adults were less likely to be married, more likely to be living alone, less likely to belong to voluntary organizations, and less likely to visit informally with others. Yet people are much more likely in the 1970s than in the 1950 s to report talking to nonprofessionals in an effort to deal with problems and crises (Veroff, Douvan, and Kulka, 1981:Ch. 9). One wonders, as with the gender differences in social support noted above, whether we may not increasingly be overloading the support resources in our society, hence often increasing stress rather than alleviating it. What factors, both cross-sectionally and over time, determine the level and patterns of social relationships in our society? And how are the changing patterns of social relationships and networks related to the experience of social support and to the quality and quantity of life? These questions must be at the heart of any comprehensive social psychological analysis of social structure and social support.

\section{REFERENCES}

Belle, Deborah $E$.

1982 "The impact of poverty on social networks and supports." Marriage and the Family Review 5(4):89-1.03.
Berkman, Lisa M.

1985 "The relationship of social networks and social support to morbidity and mortality." In Sheldon 
Cohen and S. Leonard Syme (eds.), Social Support and Health: 241-262. New York: Academic Press.

Berkman, Lisa M. and S. Leonard Syme

1979 "Social networks, host resistance and mortality: A nine-year follow-up study of Alameda County residents." American Journal of Epidemiology 109(2):186-204.

Blazer, Dan G.

1982 "Social support and mortality in an elderly community population." American Joumal of Epidemiology $115(5) ; 684-694$.

Blazer, Dan G., Linda K. George, Richard Landerman, Margaret Pennybacker, Mary Lou Melville, Max Woodbury, Kenneth G. Manton, Kathleen Jordan, and Ben Locke

1985 "Psychiatric disorders: A rural/ur. ban comparison." Archives of General Psychiatry 43:651-656.

Broadhead, W. Eugene, Berton H. Kaplan, Sherman A. James, Edward H. Wagner, Victor J. Schoenbach, Roger Grimson, Siegfried Heyden, Gosta Tibblin, and Stephen H. Gehbach

1983 "The epidemiologic evidence for a relationship between social support and health." American Joumal of Epidemiology 117(5):521-537.

Cobb, Sidney

1976 "Social support as a moderator of life stress." Psychosomatic Medicine 38(5):300-314.

Cobb, Sidney and Stanislav V. Kasl

1977 Termination: The Consequences of Job Loss. U.S. Department of Health, Education and Welfare, HFW Publication No. (NIOSH) $77-224$.

Cohen, Sheldon and S. Leonard Syme

1985 Social Support and Health. New York: Academic Press.

Cohen, Sheldon and Thomas A. Wills

1985 "Stress, social support, and the buffering hypothesis: An integrative review." Psychological Bulletin 98(2):310-357.

Dohrenwend, Barbara $S$. and Bruce $P$. Dohrenwend

1970 "Class and race as status-related sources of stress." In Sol Levine and Norman A. Scotch (eds.), Social Stress: 111-140. Chicago: Aldine.

Fischer, Claude

1982 To Dwell Among Friends. Chicago: University of Chicago Press.

\section{Gottlieb, Benjamin}

1983 "Social support as a focus for integrative research in psychology." American Psychologist 38:278-287.

1985 "Social support and community mental health." In Sheldon Cohen and S. Leonard Syme (eds.), Social Support and Health: 303-326. New York: Academic Press.

Gurin, Gerald, Joseph Veroff, and

Sheila Feld

1960 Americans View Their Mental Health. New York: Basic Books.

Hall, Alan and Barry Wellman

1985 "Social networks and social sup" port." In Sheldon Cohen and $S$. Leonard Syme (eds.), Social Support and Health: 23-41. New York: Ac. ademic Press.

Heller, Kenneth

1979 The effects of social support: Prevention and treatment implications. In A. P. Goldstein and F. H. Kanter, Maximizing Treatment Gains: Transfer Enhancement in Psychotherapy: 353-382. New York: Academic Press.

House, James $\mathbf{S}$.

1977 "The three faces of social psychology." Sociometry 40:161-177.

1981 a Work Stress and Social Support. Reading, MA: Addison-Wesley.

1981b "Social structure and personality." In Morris Rosenberg and Ralph Turner (eds.), Sociological Perspectives on Social Psychology: 525-561. New York: Basic Books.

1986 "Social support, and the quality and quantity of life." In Frank Andrews (ed.), Research on the Quality of Life: 254-269. Institute for Social Research Monograph Series, Univer. sity of Michigan, Ann Arbor.

House, James $\$$. and Robert L. Kahn

1985 "Measures and concepts of social support." In Sheldon Cohen and S. 
Leonard Syme (eds.), Social Support and Health: 83-108. New York: Academic Press.

House, James S., Cynthia Robbins, and Helen L. Metzner

1982 "The association of social relationships and activities with mortality: Prospective evidence from the $\mathrm{Te}$ cumseh Community Health Study." American Journal of Epidemiology $116(1): 123-140$.

Istael, Barbara A. and Kathleen $A$.

Rounds

forthcoming "Social networks and social support: A synthesis for health educators." Advances in Health Education and Promotion.

Kanter, Rosabeth Moss

1977 Work and Family in the United States: A Critical Review and Agenda for Research and Policy. New York: Russell Sage Foundation.

Kessler, Ronald C. and Jane D.

Mcleod

1984 "Sex differences in vulnerability to undesirable life events." American Sociological Review 49:620-631.

1985 "Social support and mental health in community surveys." In Sheldon Cohen and S. Leonard Syme (eds.), Social Support and Health: 219-240. New York: Academic Press.

Moody, Philip M. and Robert M. Gray

1972 "Social class, social integration, and the use of preventive health services." In E. Gartly Jaco (ed.), Paticnts, Physicians and Illness: 250261. New York: Free Press.
Pilisuk, M. and M. Minkler

1985 "Supportive ties: A political economy perspective." Health Education Quarterly 12(1):93-106.

Schoenbach, Victor I., Berton $H$.

Kaplan, Lisa Fredman, and David G.

Kleinbaum

1986 "Social tics and mottality in Evans County, Georgia." American Joumal of Epidemiology 123(4):577-591:

Veroff, Joseph, Elizabeth Douvan, and

Richard A. Kullka

1981 The Inner American: A Self-Portrait from 1957 to 1976. New York: Basic Books.

Veroff, Joseph, Richard A. Kulka, and Elizabeth Douvan

1981 Mental Health in America: Patterns of Help-Seeking from 1957 to 1976. New York: Basic Books.

Wethington, Elaine and Ronald $\mathrm{C}$.

Kessler

1986 "Perceived support, received support, and adjustment to stressful life events." Journal of Health and Social Behavior 27:78-89.

Wheeler, Ladd, Harry T. Reis, and John Nezlek

1983 "Loneliness, social interaction, and sex roles." Journal of Personality and Social Psychology 45:943-953.

Wortman, Camille and Darrin Lehman

1985 "Reactions to victims of life crises: Support attempts that fail." In I. G. Sarason and B. R. Sarason (eds.), Social Support: Theory, Research and Applications: 463-489. Dordrecht, Netherlands: Martinus Nijhoff.

\title{
Braudel's Ecological Perspective
}

\author{
James R. Hudson \\ Pennsylvania State University at Harrisburg
}

Fernand Braudel, a leading figure in the Annales school of French historiography, employed principles and practices from several social science disciplines in his historical studies. Significant among 